\title{
Identification and characterization of cancer stem-like cells from primary carcinoma of the cervix uteri
}

\author{
DINGQING FENG ${ }^{1}$, CHENG PENG $^{2}$, CAIRONG LI ${ }^{1}$, YING ZHOU $^{1}$, \\ MIN LI ${ }^{1}$, BIN LING $^{1,2}$, HAIMING WEI $^{3}$ and ZHIGANG TIAN ${ }^{3}$ \\ ${ }^{1}$ Anhui Province Key Laboratory of Molecular Medicine, ${ }^{2}$ Department of Obstetrics and Gynecology, \\ Anhui Provincial Hospital Affiliated to Anhui Medical University, 17 Lu-Jiang Road, Hefei 230001; \\ ${ }^{3}$ Institution of Immunology, Hefei National Laboratory for Physical Science at Microscale and School of \\ Life Science, University of Science and Technology of China, 443 Huang-Shan Road, Hefei 230027, P.R. China
}

Received March 12, 2009; Accepted May 8, 2009

DOI: $10.3892 /$ or_00000545

\begin{abstract}
Like many other solid tumors, cervical cancer contains a heterogeneous population of cancer cells. Several investigators have identified putative stem cells from solid tumors and cancer cell lines via the capacity to self renew and drive tumor formation. The aim of this study was to identify and characterize a cancer stem-like cell population from primary carcinoma of the cervix uteri. Cervical carcinoma from 19 patients staged I-II following International Federation of Gynecology and Obstetrics (FIGO) criteria were disaggregated and subjected to growth conditions selective for stem cells. Eight of nineteen tumor-derived cultures encompassed stem-like cells capable of self-renewal, extensive proliferation as clonal non-adherent spherical clusters. Cell markers of spheroid were identified as $\mathrm{CD} 44^{+} \mathrm{CK} 17^{+}$. Cell survival assays showed the sphereforming cells were only $48 \%$ inhibited by doxorubicin whereas $78 \%$ inhibited by paclitaxel. Chemo-resistance may partly attribute to the exclusive expression of $\mathrm{ABC}$ transporter. To investigate the tumorigenicity of these stemlike cells, xenoengraftment of $10^{5}$ dissociated spheroid cells allowed full recapitulation of the original tumor, whereas the same amount of tumor cells without non-adherent spheroid selection remained non-tumorigenic. Stemness properties of these spheroid cells were further established by reverse transcription-PCR and Western blotting, demonstrating the expression of embryonic and adult stemness-related genes (Oct-4, Piwil2, C-myc, Stat3 and Sox2). Based on these findings, we assert that cervical cancer contain a subpopulation of tumor initiating cells with stem-like properties, thus
\end{abstract}

Correspondence to: Dr Bin Ling, Department of Obstetrics and Gynecology, Anhui Provincial Hospital Affiliated to Anhui Medical University, 17 Lu-Jiang Road, Hefei 230001, P.R. China

E-mail: lingbin.ling@gmail.com

Key words: cancer stem cell, cervical cancer, CD44, CK17 facilitating the approach to therapeutic strategies aimed at eradicating the tumorigenic subpopulation within cervical cancer.

\section{Introduction}

Cervical cancer is one of the most frequent diseases in women and a considerable cause of morbidity and mortality among them. It is the second most frequent type of cancer in women worldwide, preceded only by breast cancer $(1,2)$; each year $\sim 500,000$ women worldwide are diagnosed with invasive cervical cancer and more than half of them die of this disease. Eighty percent of these deaths occur in developing countries. It is therefore essential that we develop a deeper understanding of the biology of this disease to develop more effective therapies.

An increasing number of studies have shown the association between high-risk human papilloma virus (HPV) infection and cervical carcinogenesis, which leads to ongoing mutations and cellular heterogeneity $(3,4)$. A growing body of evidence has been reported supporting the notion that tumors are organized in a hierarchy of heterogeneous cell populations with different biological properties and that the capability to sustain tumor formation and growth exclusively resides in a small proportion of tumor cells, termed cancer stem cells (CSCs) or tumor-initiating cells (TICs) (5-7). TICs have been identified in multiple myeloma (8), cancer cell lines $(9,10)$ and in solid tumors of the breast, ovary, endometrum, prostate, brain, and lung (11-16), through an experimental strategy that combines sorting of tumor cell subpopulations, identified on the basis of the different expression of surface markers, with functional transplantation into appropriate animal models. These studies have shown that TICs are responsible for tumor formation and progression and, interestingly, that they are endowed with stem/progenitor cell properties; in particular, TICs share with stem cells the key feature of self-renewal.

The stem cell-like phenotype of TICs and their limited number within the bulk of the tumor may account for their capability to escape conventional therapies, thus leading to disease relapse although the primary lesion is eradicated; 
hence, the importance to develop therapeutic strategies capable of affecting tumor-initiating as well as non-tumorigenic cells survival. Accordingly, the establishment of long-term cultures of TICs would represent a step of crucial importance, providing a suitable in vitro model for these cells to be studied. On this basis and referring to the research of Kondo et al (10), who identified the existence of a small side population (SP) that is enriched for cells with the characteristics of cancer stem cells in the human adenocarcinoma line HeLa, we tried to verify the presence of a sub-population of cervical cancerderived cells that is tumorigenic and displays some stem cell-like properties.

\section{Materials and methods}

Primary tumor sphere culture. All studies were approved by the Ethics Committee of Anhui Provincial Hospital Affiliated to Anhui Medical University. Tumor specimens were obtained from 19 cervical cancer patients, staged following International Federation of Gynecology and Obstetrics (FIGO) criteria: IA 5, IB 9, IIA 3 and IIB 2. Tumors were washed with $1 \mathrm{X}$ PBS containing penicillin/streptomycin $(10,000 \mathrm{U} / \mathrm{ml}$ and $10,000 \mathrm{mg} / \mathrm{ml}$, respectively), mechanically dissociated and subjected to enzymatic digestion. The tissue fragments were incubated at $37^{\circ} \mathrm{C}$ for $3 \mathrm{~h}$ in $0.6 \%$ collagenase (Gibco, USA) and then for $10 \mathrm{~min}$ in $0.25 \%$ trypsin (Amresco, USA). After filtered through a $30-\mu \mathrm{m}$ cell strainer and red blood cell (RBC) lysis, the resulting single tumor cells were plated at $1 \times 10^{5}$ cells/well (6-well plate, Greiner, Germany) in serum-free DMEM-F12 (Gibco), supplemented with $10 \mathrm{ng} / \mathrm{ml}$ basic fibroblast growth factor (bFGF, PeproTech, USA), $20 \mathrm{ng} / \mathrm{ml}$ epidermal growth factor (EGF, PeproTech), $5 \mu \mathrm{g} / \mathrm{ml}$ insulin (Sigma, USA), $1 \mathrm{mM} \mathrm{L-glutamine}$ (Sigma), 2\% B27 (Gibco) and penicillin/streptomycin $(1,000 \mathrm{U} / \mathrm{ml}$ and $1,000 \mathrm{mg} / \mathrm{ml}$, respectively). Stem cells grown in these conditions usually formed non-adherent spherical clusters (also named 'spheres').

Sphere formation assay. Primary spheres were enzymatically dissociated by incubation in a trypsin-EDTA solution for $2 \mathrm{~min}$ at $37^{\circ} \mathrm{C}$ and plated in 96-well culture dishes (Greiner) at 100 cells per well in $200 \mu 1$ of growth medium; $25 \mu 1$ of medium per well were added every 2 days. The number of spheres for each well was evaluated after 7 days of culture.

Flow cytometric analysis. By using a FACScan (Beckman), the cell markers were distinctly evaluated on cells obtained from spheres. FITC-anti-CD34, PE-cy5-anti-CD44 and PEanti-CD105 were obtained from eBioscience and anti-CK17 (indirectly conjugated with FITC) from Pierce. Staining was done according to the instructions of the manufacturer. For staining of membrane antigens (CD34, CD44 and CD105), unfixed cells were allowed to recover in fresh medium for $1 \mathrm{~h}$ at $37^{\circ} \mathrm{C}$ in gentle agitation after dissociation. Conversely, before staining of cytoplasmic antigens CK17, single cells were fixed in $70 \%$ ethanol at $-20^{\circ} \mathrm{C}$ for $10 \mathrm{~min}$.

Growth inhibition by chemotherapeutics in vitro. MTT assay was used to assess proliferation inhibition. Cells derived from sphere were plated in the inner wells of 96-well plates at
1,000 cells per well in $200 \mu 1$ of medium per well. Twenty-four hours after plating, each set of 6-wells of sphere-derived cells was treated with $100 \mathrm{nM}$ paclitaxel (Bristol-Myers Squibb Co., USA), a 100-nM doxorubicin hydrochloride injection (Pfizer Inc., USA), or media alone. At day 7 of incubation, cell viability was quantified by measuring mitochondrial activity on an ELISA plate reader at an absorbance of $570 \mathrm{~nm}$ to generate an OD proportional to the relative abundance of live cells in a given well.

Mouse model for analyses of tumorigenicity. Spheres were collected, enzymatically dissociated, washed in PBS and kept at $4^{\circ} \mathrm{C}$ until subcutaneously injected into 5-week-old female nude mice $\left(10^{5}\right.$ cells/animal $)$ in the dorsal side between the scapulae. Equal amount of tumor cells without non-adherent spheroid selection were injected into another 3 mice as the control. Mice were maintained in laminar flow rooms under constant temperature and humidity. Mice were inspected for tumor appearance, by observation and palpation, for 12 weeks following cell injection; after this time interval, all mice were sacrificed by cervical dislocation and the presence of each tumor nodule was confirmed by necropsy. All experiments utilizing mouse models were performed in strict accordance with policies on the care and use of laboratory animals of the Ethics Committee of Anhui Provincial Hospital Affiliated to Anhui Medical University.

Immunohistochemistry. At sacrifice, nodules grown in mice were immediately removed, fixed in $4 \%$ paraformaldehyde and embedded in paraffin. Four-micrometer-thick sections were cut, mounted on poly-L-lysine-coated slides, dried $3 \mathrm{~h}$ at $56^{\circ} \mathrm{C}$, dewaxed in xylene, rehydrated according to histopathologic procedures and stained with $\mathrm{H} \& \mathrm{E}$. For determining factor VIII immunoreactivity, antigen retrieval was performed by microwaving in $0.1 \mathrm{M}$ citrate buffer, $\mathrm{pH} 6.0$, for $10 \mathrm{~min}$ and cooling to room temperature. Sections were incubated overnight at $4^{\circ} \mathrm{C}$ with anti-human factor VIII primary antibody (Boster, China). Immunodetection was done using the ChemMate Detection kit (Boster). After visualized with diaminobenzidine chromogen, slides were lightly counterstained with Mayer's haematoxylin for $30 \mathrm{sec}$.

Biological characterization of sphere-derived cells. Total RNA was extracted from spheroid cells using TRIzol (Invitrogen, USA). RNA was reverse-transcribed using cDNA Synthesis kit (Promega, USA). cDNA was amplified using $1 \mu \mathrm{l}$ of the reverse transcriptase reaction products in $25 \mu 1$ with $10 \mathrm{pmol}$ of the primers for 35 cycles. Each cycle consisted of $40 \mathrm{sec}$ of denaturation at $94^{\circ} \mathrm{C}, 40 \mathrm{sec}$ of annealing and $40 \mathrm{sec}$ of extension at $72^{\circ} \mathrm{C}$. The PCR products were electrophoresed on a $1 \%$ agarose gel and visualized by ethidium bromide staining. The primer sequences used for cDNA amplification (forward and reverse) are listed in Table I. ß-actin was used as the internal control in all reactions.

Expression of Piwil2 and Oct-4 was evaluated by Western blotting. Total cellular lysates were separated on an $8 \%$ SDSpolyacrylamide gel and transferred to polyvinylidene fluoride (PVDF) membranes (Millipore, USA). Filters were blocked in TBS with 5\% skim-milk and incubated overnight with the primary antibody anti-Piwil2 (Santa Cruz, USA) and anti-Oct-4 
Table I. PCR primers used for expression analysis of the tumor-derived spheroids.

\begin{tabular}{|c|c|c|}
\hline Primer name & Forward primer & Reverse primer \\
\hline$A B C G 2$ & GGGTTCTCTTCTTCCTGACGACC & TGGTTGTGAGATTGACCAACAGACC \\
\hline Sox2 & CCCCCGGCGGCAATAGCA & TCGGCGCCGGGGAGATACAT \\
\hline Oct-4 & GACAACAATGAAAATCTTCA & TTCTGGCGCCGGTTACAGAA \\
\hline$C-m y c$ & TGAAAGGCTCTCCTTGCAGC & GCTGGTAGAAGTTCTCCTCC \\
\hline Piwil2 & ATCGCCCTCTGGTCCTGACTGT & CACATTGGGGCTGAAAGTCACA \\
\hline Stat3 & TTGCCAGTTGTGGTGATC & AGAACCCAGAAGGAGAAGC \\
\hline$\beta$-actin & GTGGGGCGCCCCAGGCACCA & CTCCTTAATGTCACGCACGATTT \\
\hline
\end{tabular}

A

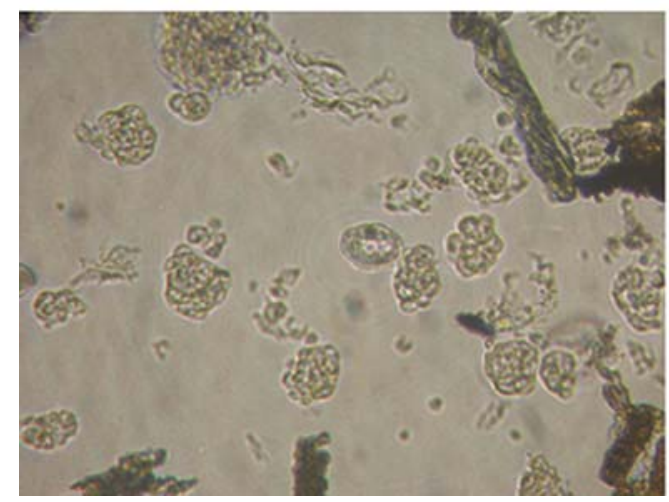

B

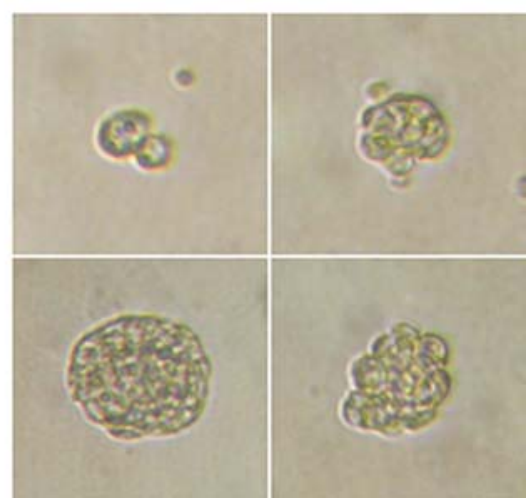

Figure 1. The morphology of tumor spheres. (A) Primary culture of isolated cervical cancer cells growing as non-adherent spheres (x100). (B) Generation of a sphere from a single cell (x200).
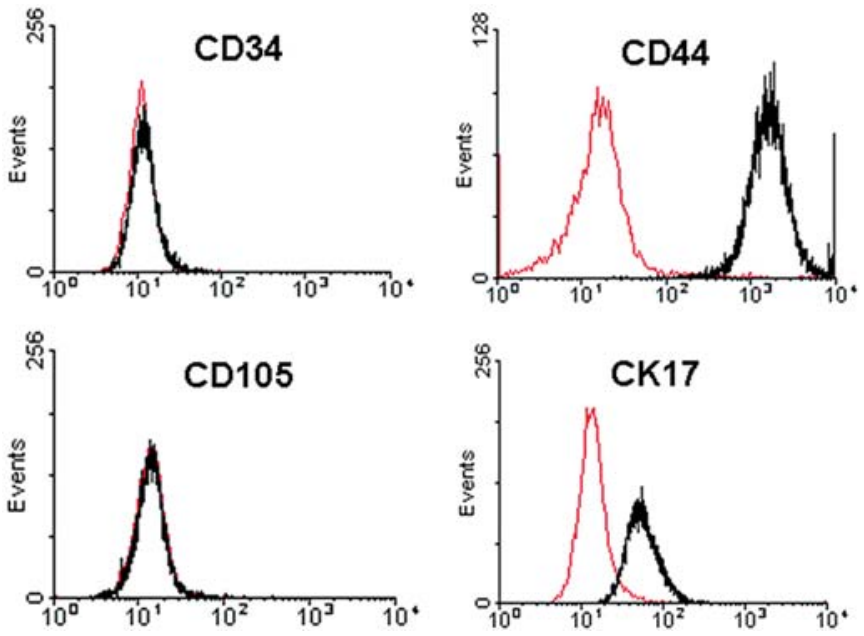

Figure 2. Fluorescence-activated cell sorting (FACS) analysis of CD34, CD105, CD44 and CK17 expression in cervical cancer cells grown in serum-free medium as non-adherent spheres. These cells were uniformly negative for CD34, CD105 and positive for CD44, CK17.

(Abcam, UK). Filters were then incubated with secondary peroxidase-linked antibody (Boster). Detection was done by enhanced chemiluminescence Western blotting detection system (Thermo, USA). Anti- $\beta$-actin (Boster) was used to ensure equal loading of protein on the gel.
Statistical analysis. The Student's t-test was used for statistical comparisons where appropriate. A P-value of $<0.05$ for the t-test was considered to be statistically significant. The Statistical Package for Windows version 11 (SPSS Inc., Chicago, IL, USA) was used for all statistical analyses.

\section{Results}

Establishment of primary cultures of stem-like cells from cervical cancer. In 8 of 19 cases (denoted as T1-T8, 1 of 5 IA, 3 of 9 IB, 2 of 3 IIA and 2 IIB), 10 to 15 days after plating the formation of non-adherent spheres could be observed in culture (Fig. 1A). Primary spheres could be enzymatically dissociated to single cells, which in turn gave rise to secondary spheres (Fig. 1B); this procedure could be repeated, leading to an extensive amplification in cell number. Using this approach, we obtained sustainable spheroids from T1-T8 under stem cell conditions establishing the ability of these anchorageindependent structures to self-renew.

Sphere-forming cells from cervical cancer express CD44 and CK17. The sphere-forming cells were negative for CD34 and CD105, which were typical hematopoietic antigen and marker of mesenchymal stem cells, respectively, and positive for CD44 and CK17 (Fig. 2).

Sphere-derived cells are resistant to chemotherapeutic drugs. RT-PCR was carried out in these spheroid cells from T1-T8 
A

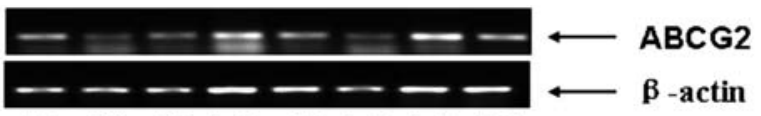

$\begin{array}{llllllll}\text { T1 } & \text { T2 } & \text { T3 } & \text { T4 } & \text { T5 } & \text { T6 } & \text { T7 } & \text { T8 }\end{array}$
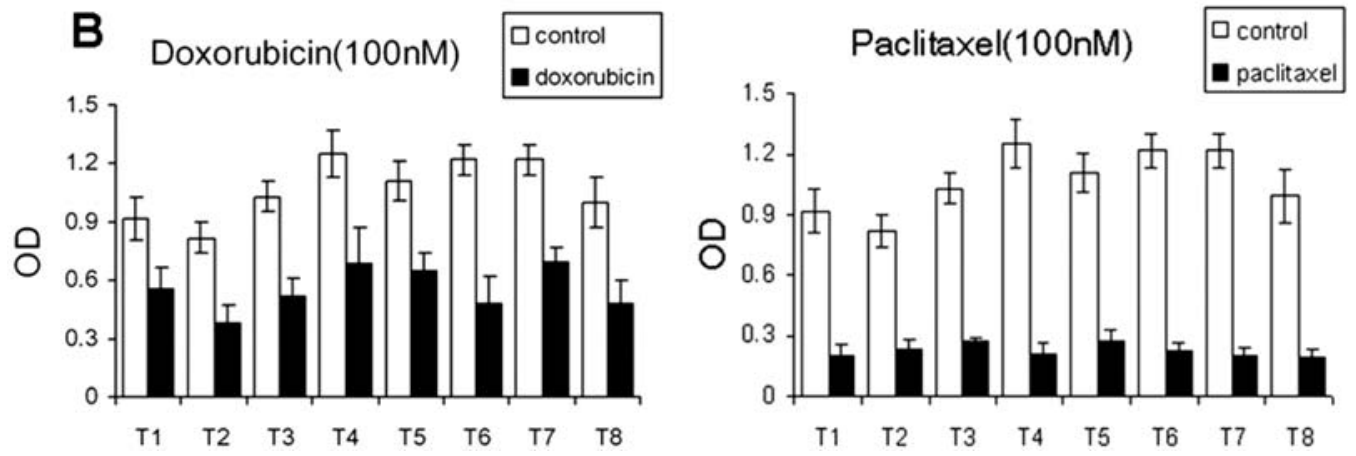

Figure 3. Chemoresistance of sphere-forming cells. (A) As shown by RT-PCR, these sphere-forming cells derived from T1-T8 exclusively expressed ABCG2. (B) These sphere-forming cells were sorted for MTT growth-inhibition analysis against doxorubicin and paclitaxel. Spheroid cells showed, on average, $48 \%$ inhibition by doxorubicin and $78 \%$ inhibition by paclitaxel compared with vehicle-treated controls.

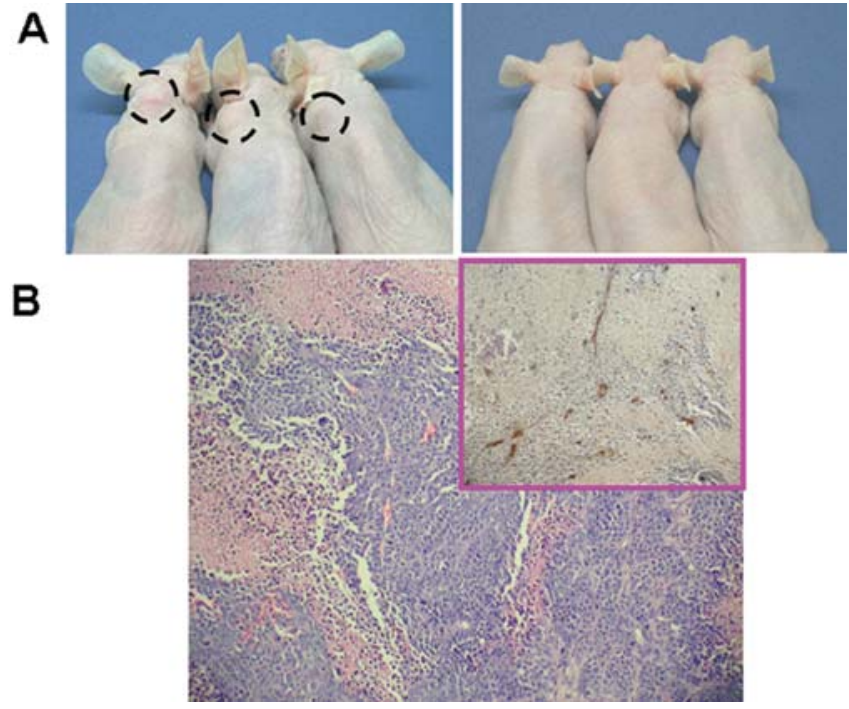

Figure 4. Subcutaneous tumorigenicity of sphere-forming cells in nude mice. (A) Xenograft tumor formed in nude mice 10 weeks after injection of $10^{5}$ sphere-forming cells derived from patient tumors $\mathrm{T} 5$ and $\mathrm{T} 7$, whereas no evident tumor formation was observed in the mice injected with $10^{5}$ unselected tumor cells after 12 weeks. (B) A representative section (x100) of tumor grown in nude mice following the injection of isolated sphere-forming cells (H\&E). Tumor neovascularization were observed in these sections as shown by anti-human factor VIII staining (pink frame, x100).

to identify the expression of $\mathrm{ABC}$ transporters. The result showed that $A B C G 2$ was exclusively expressed in T1-T8 (Fig. 3A). To further investigate the functional significance of the $A B C G 2$ transporter in these sphere-forming cells derived from T1-T8, we examined their response to doxorubicin and paclitaxel by methylthiazoletetrazolium (MTT) proliferation assays. All of these cells from T1-T8 were only inhibited by $48 \%$ after treatment with doxorubicin, whereas $78 \%$ were inhibited by the ABCG2-resistant paclitaxel (Fig. 3B).

Tumor-initiating capability of isolated cervical cancer stem-like cells. Tumors appeared in three of three animals at
A

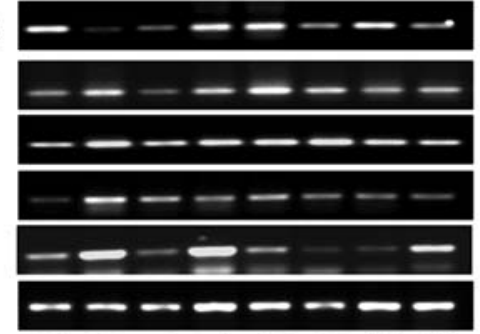

Oct-4

Piwil2

C-myc

Stat3

Sox2

$\beta$-actin

$\begin{array}{llllllll}\text { T1 } & \text { T2 } & \text { T3 } & \text { T4 } & \text { T5 } & \text { T6 } & \text { T7 } & \text { T8 }\end{array}$

B

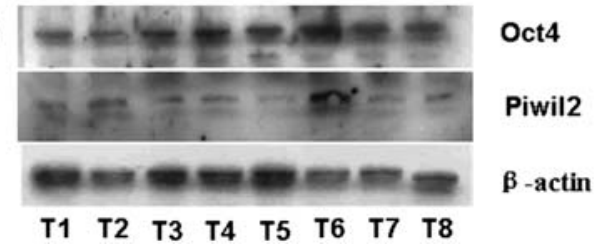

Figure 5. The expression of embryonic and adult stemness-related genes. (A) RT-PCR analyses of the expression of embryonic and adult stemnessrelated genes (Oct-4, Piwil2, C-myc, Stat3 and Sox2) in these sphere-forming cells derived from T1-T8. (B) Analysis by Western blotting of the expression of the putative stem cell markers Oct-4 and Piwil2 in these cells.

10 weeks after injection of $10^{5} \mathrm{~T} 5$ or $\mathrm{T} 7$ sphere-forming cells, whereas animals injected with an equal number of tumor cells without non-adherent spheroid selection had no detectable tumors (zero of three) until 12 weeks (Fig. 4A). H\&E staining of tumors grown in mice revealed the presence of malignant cells and exhibited a high degree of similarity with the primary tumor in the patient. Moreover, high vessel density was observed after human factor VIII staining (Fig. 4B).

Sphere-derived cells express embryonic and adult stemnessrelated genes. Since these sphere-forming cells exhibited the properties of stem cells, as well as the potency of tumorigenesis, we examined the expression of embryonic and adult stemness-related genes in these cells: Oct-4, Piwil2, C-myc, Stat3 and Sox2. As shown in Fig. 5, both embryonic and adult stem cell-related genes were detected in these sphere-forming 
cells, providing further evidence for their undifferentiated phenotype and tumorigenesis.

\section{Discussion}

The CSC hypothesis suggests that only the CSCs within the tumor can self-renew and proliferate extensively to form new tumors. It has been demonstrated for several different types of cancer that a distinct subset of cells initiates tumors in vivo, whereas the remaining cells do not $(8,11-17)$. Further evidence for the CSC hypothesis comes from clinical observations, where tumors often respond to chemotherapy initially, but frequently recur, suggesting that residual stem cells remaining after therapy are responsible for tumor regeneration. In cervical cancer, as in other cancers, characterization of CSCs will allow for the development of new treatments that are specifically targeted against this critical population of cells, particularly their ability to self-renew, resulting in more effective therapies.

In this study, we have provided evidence for the existence of a developmental hierarchy within human cervical cancer; that is, human cervical cancer contain a subpopulation of tumorigenic cancer cells with both self-renewal and chemoresistance capacity.

Initially, to identify candidate of cancer stem-like cells, we cultured disaggregated tumor cells from primary carcinoma of the cervix uteri under stem cell-selective conditions. A small minority of cells could survive and form anchorageindependent clusters. Because the ability of growing as spherical clusters does not show per se the presence in culture of self-renewing cells, spheroid formation assay was examined; clonal, non-adherent spheres formed, which in turn gave rise to long-term cultures, thus providing definitive evidence for the presence of self-renewing cells in cervical cancer $(13,18,19)$.

Sphere-derived cells did not express CD34 and CD105, which excluded the possibility of haemopoietic and mesenchymal stem cells. These cells were positive for CD44, which was closely correlated with invasion and metastasis of tumor, and univocally expressed in tumor-initiating cells of epithelial origin $(17,18,20)$. Furthermore, they were positive for CK17, a marker of the HPV target cell-cervical reserve (stem) cell, which give rise to metaplasia $(21,22)$. These may provide important insight into understanding recurrence and metastasis of cervical cancer and, to some extent, the genesis of tumorinitiating cells. The genetic mutation resulting from high-risk HPV infection led the stem cells to undergo uncontrolled proliferation and possible tumorigenesis (23).

To verify the undifferentiated phenotype of these tumorderived spheroids, some gene markers were detected. We found that these sphere-forming cells exclusively expressed Oct-4 and Sox2, the embryonic stem cell (ESC)-related stemness gene (24). Moreover, Piwil2, a member of $P I W I / A G O$ gene family, which is exclusively expressed in testis and essential for stem cell self-renewal (25), gametogenesis (26), small RNA-mediated gene silencing (27), and translational regulation in various organisms (27), was stably expressed in spheroid cells. These genes have a conserved function in stem cell division (25). It is possible that these stemness genes confer the sphere-forming cells the maintenance of undifferentiated state and pleuripotency $(24,25,28)$. Lee et al (29) reported that overexpression of Piwil2 in NIH3T3 cells led to inhibition of apoptosis and promotion of proliferation via the $S t a t 3 / B c l-X(L)$ signaling pathway. $C$-myc was also closely associated with stem cell proliferation (30). To further confirm these, our results showed that the sphere-forming cells from T1-T8 exclusively expressed Stat3 and C-myc.

Cervical cancer patients initially respond well to neoadjuvant chemotherapy and surgical cytoreduction. Neoadjuvant chemotherapy alone can yield several logs of tumor cytoreduction but seldom a cure. The majority of patients who respond to primary chemotherapy ultimately develop recurrent and metastatic disease that is conceivably due to, as occurring in other gynecological tumors, the development of a drug-resistant phenotype. One increasingly accepted hypothesis of chemoresistance posits that standard therapies fail to target tumor progenitors, which are believed to express normal stem cell phenotypes, especially expression of membrane efflux transporters (e.g., ABCG2); $(9,12,13,17,31)$. The ABCG2 transporter confers the ability to the drug resistance-associated efflux of many lipophilic chemotherapeutic agents such as mitoxantrone, daunorubicin, doxorubicin, indolcarbazole and others (32). Consistently, our results showed that these sphere-forming cells, under stem cell-selective conditions, exclusively express $A B C G 2$ and are more resistant to doxorubicin, confirming these stem cell-like characteristics as a potential mechanism for drug resistance.

Our in vitro analyses suggest that these sphere-forming cells derived from cervical cancer have the stem cell-like properties of self-renew and chemoresistance. To test in vivo tumorigenicity we injected equal numbers $\left(10^{5}\right)$ of spheroid cells and tumor cells without non-adherent spheroid selection into nude mice. All of the mice injected with spheroid cells developed tumors 10 weeks post-injection, whereas no evident tumor formation was observed in the mice injected with the unselected tumor cells after 12 weeks, demonstrating that the cervical cancer derived sphere-forming cells were enriched for tumor initiating activity. Moreover, sphere-forming cells injection resulted in graft tumors histologically identical to the original primary tumor and tumor neovascularization. Cancer stem cells have been shown to promote tumor angiogenesis through secreting growth factor VEGF (33) and might have the capacity to form blood vessels in tumorigenic environments via transdifferentiation into endothelial-like cells $(34,35)$. These may verify the pleuripotency of CSCs, and, to some extent, explain why anti-angiogenic cancer therapy trails are facing serious challenge (36).

Collectively, our results provide evidence to suggest that $\mathrm{CD} 44^{+} \mathrm{CK} 17^{+} /$sphere-forming cervical cancer cells display stem cell properties. Under optimal environmental conditions these cervical cancer stem-like populations are predicted to show self-renewal, chemoresistance, and in vivo tumorigenicity, thereby promoting recurrence of the cancer and possibly metastasis. This experimental system may represent a suitable in vitro model to study cervical cancer stem-like cells and to challenge them with molecularly targeted agents specifically interfering with cervical cancer stem-like cell self-renewal and survival. 


\section{Acknowledgements}

We thank Dr Huai-ping Zhu (The University of Oklahoma, Health Sciences Center) and Dr Hai-long Hou (Louisiana State University Health Sciences Center) for helpful comments and critical reading of the manuscript. This study was supported by grants from National Natural Science Foundation of China (NSFC, No. 34071805), Science and Technology Key Projects of Anhui Province (No. 06013124B).

\section{References}

1. Ferenczy A and Franco E: Persistent human papillomavirus infection and cervical neoplasia. Lancet Oncol 3: 11-16, 2002.

2. Tjalma WA, Van Waes TR, Van den Eeden LE and Bogers JJ: Role of human papillomavirus in the carcinogenesis of squamous cell carcinoma and adenocarcinoma of the cervix. Best Pract Res Clin Obstet Gynaecol 19: 469-483, 2005.

3. Werness BA, Levine AJ and Howley PM: Association of human papillomavirus types 16 and 18 E6 proteins with $\mathrm{p} 53$. Science 248: 76-79, 1990

4. Nindl I, Rindfleisch K, Lotz B, Schneider A and Durst M Uniform distribution of HPV 16 E6 and E7 variants in patients with normal histology, cervical intra-epithelial neoplasia and cervical cancer. Int J Cancer 82: 203-207, 1999.

5. Reya T, Morrison SJ, Clarke MF and Weissman IL: Stem cells, cancer, and cancer stem cells. Nature 414: 105-111, 2001.

6. Marx J: Cancer research. Mutant stem cells may seed cancer. Science 301: 1308-1310, 2003

7. Pardal R, Clarke MF and Morrison SJ: Applying the principles of stem-cell biology to cancer. Nat Rev Cancer 3: 895-902, 2003

8. Matsui W, Huff CA, Wang Q, et al: Characterization of clonogenic multiple myeloma cells. Blood 103: 2332-2336, 2004

9. Hirschmann-Jax C, Foster AE, Wulf GG, et al: A distinct 'side population' of cells with high drug efflux capacity in human tumor cells. Proc Natl Acad Sci USA 101: 14228-14233, 2004.

10. Kondo T, Setoguchi T and Taga T: Persistence of a smal subpopulation of cancer stem-like cells in the C6 glioma cell line. Proc Natl Acad Sci USA 101: 781-786, 2004.

11. Al-Hajj M, Wicha MS, Benito-Hernandez A, Morrison SJ and Clarke MF: Prospective identification of tumorigenic breast cancer cells. Proc Natl Acad Sci USA 100: 3983-3988, 2003

12. Szotek PP, Pieretti-Vanmarcke R, Masiakos PT, et al: Ovarian cancer side population defines cells with stem cell-like characteristics and Mullerian Inhibiting Substance responsiveness. Proc Natl Acad Sci USA 103: 11154-11159, 2006.

13. Friel AM, Sergent PA, Patnaude C, et al: Functional analyses of the cancer stem cell-like properties of human endometrial tumor initiating cells. Cell Cycle 7: 242-249, 2008.

14. Collins AT, Berry PA, Hyde C, Stower MJ and Maitland NJ: Prospective identification of tumorigenic prostate cancer stem cells. Cancer Res 65: 10946-10951, 2005.

15. Singh SK, Hawkins C, Clarke ID, et al: Identification of human brain tumour initiating cells. Nature 432: 396-401, 2004.

16. Ho MM, Ng AV, Lam S and Hung JY: Side population in human lung cancer cell lines and tumors is enriched with stem-like cancer cells. Cancer Res 67: 4827-4833, 2007.

17. Zhang S, Balch C, Chan MW, et al: Identification and characterization of ovarian cancer-initiating cells from primary human tumors. Cancer Res 68: 4311-4320, 2008.
18. Ponti D, Costa A, Zaffaroni N, et al: Isolation and in vitro propagation of tumorigenic breast cancer cells with stem/ progenitor cell properties. Cancer Res 65: 5506-5511, 2005.

19. Dontu G, Abdallah WM, Foley JM, Jackson KW, Clarke MF, Kawamura MJ and Wicha MS: In vitro propagation and transcriptional profiling of human mammary stem/progenitor cells. Genes Dev 17: 1253-1270, 2003.

20. Prince ME, Sivanandan R, Kaczorowski A, et al: Identification of a subpopulation of cells with cancer stem cell properties in head and neck squamous cell carcinoma. Proc Natl Acad Sci USA 104: 973-978, 2007.

21. Martens JE, Arends J, Van der Linden PJ, De Boer BA and Helmerhorst TJ: Cytokeratin 17 and p63 are markers of the HPV target cell, the cervical stem cell. Anticancer Res 24: $771-775,2004$

22. Regauer S and Reich O: CK17 and p16 expression patterns distinguish (atypical) immature squamous metaplasia from highgrade cervical intraepithelial neoplasia (CIN III). Histopathology 50: 629-635, 2007.

23. Li L and Neaves WB: Normal stem cells and cancer stem cells: the niche matters. Cancer Res 66: 4553-4557, 2006.

24. Koestenbauer S, Zech NH, Juch H, Vanderzwalmen P, Schoonjans L and Dohr G: Embryonic stem cells: similarities and differences between human and murine embryonic stem cells. Am J Reprod Immunol 55: 169-180, 2006.

25. Cox DN, Chao A, Baker J, Chang L, Qiao D and Lin H: A novel class of evolutionarily conserved genes defined by piwi are essential for stem cell self-renewal. Genes Dev 12: 3715-3727, 1998.

26. Kuramochi-Miyagawa S, Kimura T, Ijiri TW, et al: Mili, a mammalian member of piwi family gene, is essential for spermatogenesis. Development 131: 839-849, 2004.

27. Carmell MA, Xuan Z, Zhang MQ and Hannon GJ: The Argonaute family: tentacles that reach into RNAi, developmental control, stem cell maintenance, and tumorigenesis. Genes Dev 16: 2733-2742, 2002.

28. Chambers I and Smith A: Self-renewal of teratocarcinoma and embryonic stem cells. Oncogene 23: 7150-7160, 2004.

29. Lee JH, Schutte D, Wulf G, et al: Stem-cell protein Piwil2 is widely expressed in tumors and inhibits apoptosis through activation of Stat3/Bcl-XL pathway. Hum Mol Genet 15: 201-211, 2006.

30. Wei C, Guomin W, Yujun L and Ruizhe Q: Cancer stem-like cells in human prostate carcinoma cells DU145: the seeds of the cell line? Cancer Biol Ther 6: 763-768, 2007.

31. Dean M, Fojo T and Bates S: Tumour stem cells and drug resistance. Nat Rev Cancer 5: 275-284, 2005.

32. Doyle LA and Ross DD: Multidrug resistance mediated by the breast cancer resistance protein BCRP (ABCG2). Oncogene 22: 7340-7358, 2003.

33. Bao S, Wu Q, Sathornsumetee S, et al: Stem cell-like glioma cells promote tumor angiogenesis through vascular endothelial growth factor. Cancer Res 66: 7843-7848, 2006.

34. Shen R, Ye Y, Chen L, Yan Q, Barsky SH and Gao JX: Precancerous stem cells can serve as tumor vasculogenic progenitors. PLoS ONE 3: e1652, 2008.

35. Gao JX: Cancer stem cells: the lessons from pre-cancerous stem cells. J Cell Mol Med 12: 67-96, 2008.

36. Medina MA, Munoz-Chapuli R and Quesada AR: Challenges of antiangiogenic cancer therapy: trials and errors, and renewed hope. J Cell Mol Med 11: 374-382, 2007. 